\title{
A water availability and low-flow analysis of the Tagliamento River discharge in Italy under changing climate conditions
}

\author{
L. N. Gunawardhana and S. Kazama \\ Department of Civil Engineering, Tohoku University, Aoba 20, Sendai, 980-8579, Japan \\ Correspondence to: L. N. Gunawardhana (luminda@kaigan.civil.tohoku.ac.jp) \\ Received: 12 December 2011 - Published in Hydrol. Earth Syst. Sci. Discuss.: 5 January 2012 \\ Revised: 13 March 2012 - Accepted: 25 March 2012 - Published: 30 March 2012
}

\begin{abstract}
This study estimated the effects of projected variations in precipitation and temperature on snowfall-snowmelt processes and subsequent river discharge variations in the Tagliamento River in Italy. A lumped-parameter, non-linear, rainfall-runoff model with 10 general circulation model (GCM) scenarios was used. Spatial and temporal changes in snow cover were assessed using 15 high-quality Landsat images. The 7Q10 low-flow probability distribution approximated by the Log-Pearson type III distribution function was used to examine river discharge variations with respect to climate extremes in the future. On average, the results obtained for 10 scenarios indicate a consistent warming rate for all time periods, which may increase the maximum and minimum temperatures by $2.3{ }^{\circ} \mathrm{C}\left(0.6-3.7^{\circ} \mathrm{C}\right)$ and $2.7^{\circ} \mathrm{C}\left(1.0_{-}\right.$ $4.0^{\circ} \mathrm{C}$ ), respectively, by the end of the $21 \mathrm{st}$ century compared to the present climate. Consequently, the exponential rate of frost day decrease for $1{ }^{\circ} \mathrm{C}$ winter warming in lowerelevation areas is approximately three-fold (262\%) higher than that in higher-elevation areas, revealing that snowfall in lower-elevation areas will be more vulnerable under a changing climate. In spite of the relatively minor changes in annual precipitation $(-17.4 \sim 1.7 \%$ compared to the average of the baseline (1991-2010) period), snowfall will likely decrease by $48-67 \%$ during the 2080-2099 time period. The mean river discharges are projected to decrease in all seasons, except winter. The low-flow analysis indicated that while the magnitude of the minimum river discharge will increase (e.g. a $25 \%$ increase in the 7Q10 estimations for the winter season in the 2080-2099 time period), the number of annual average low-flow events will also increase (e.g. 16 and 15 more days during the spring and summer seasons, respectively, in the 2080-2099 time period compared to the average during the baseline period), leading to a future with a highly variable river discharge. Moreover, a consistent shift
\end{abstract}

in river discharge timing would eventually cause snowmeltgenerated river discharge to occur approximately 12 days earlier during the 2080-2099 time period compared to the baseline climate. These results are expected to raise the concern of policy makers, leading to the development of new water management strategies in the Tagliamento River basin to cope with changing climate conditions.

\section{Introduction}

Observed and projected increases in temperature and precipitation variability are perhaps the most influential climatedriven changes to impact water systems (Parry et al., 2007). Such changes in high-elevation areas are likely to be more profound than others (Beniston, 2005). In mountainous areas, precipitation largely occurs as snow during the winter, which accumulates on the ground until adequate solar energy is available to start the melting process in spring and summer. This melting water sustains the river level downstream when rainfall decreases and when demand is high. The increasing temperature and variations in precipitation patterns evidently alter the mountain hydrology in many ways. Higher temperatures cause snow and glaciers to melt at faster rates (Schneeberger et al., 2003) and precipitation to fall more often as rain than as snow (Beniston et al., 2003). The subsequent impacts include, but are not limited to, seasonal shifts in stream flows (Zion et al., 2011), an increase in the ratio of winter to annual flows (Stewart, 2009), a reduction in low flows during spring and summer (Miller et al., 2003), increased risks of landslides (Kawagoe et al., 2009) and floods (EEA, 2009), a lack of water resources for water supply systems (Matonse et al., 2011) and hydro-power generation (Schaefli et al., 2007) and challenges to the tourist industry (Beniston, 2003). 


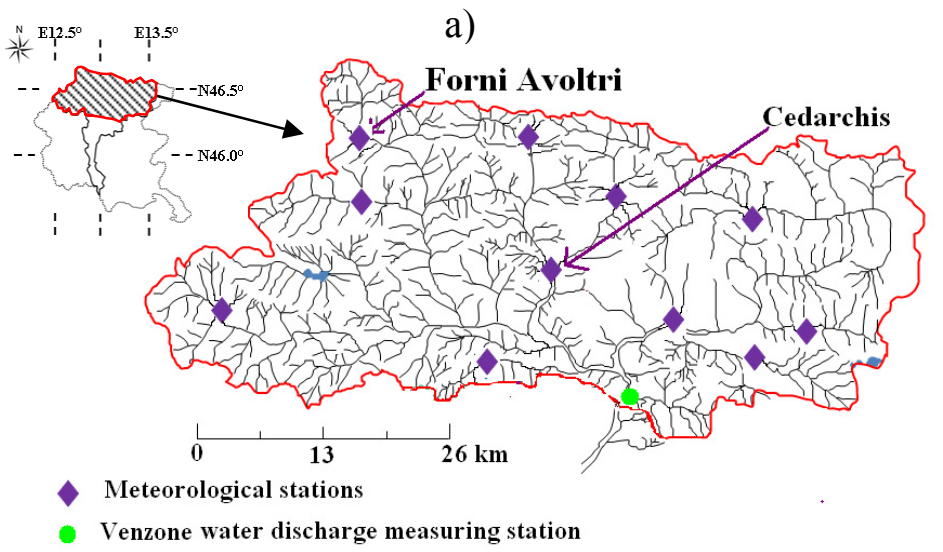

b)

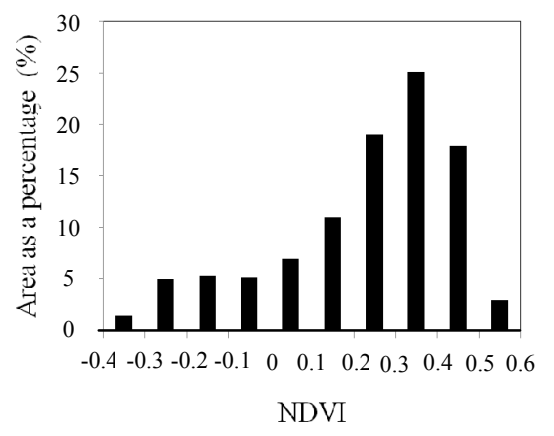

Fig. 1. (a) Catchment area representative of the Venzone water discharge measuring station and the distribution of meteorological stations within the study area. (b) NDVI composition of the catchment area derived from Landsat images taken on 29 July 2002.

The Alps, commonly known as the water tower of Europe, are among the mountains threatened by dramatic changes in water cycle mainly attributed to climate change. Alpine climates have undergone significant change over the past century. According to Beniston (2005), the warming experienced in the Swiss Alps in the 20th century has resulted in a more than $1.5^{\circ} \mathrm{C}$ increase in annual average air temperature, which is approximately a three-fold amplification in comparison to the global average warming during the same period (Diaz and Bradley, 1997). Further investigation has revealed that increases in the minimum temperature were as high as $2{ }^{\circ} \mathrm{C}$ in the European Alps during the 20th century, with a modest increase in the maximum air temperature and a slight trend in precipitation anomalies (Beniston, 2000). Based on 44 yr climatic records (1958-2002), Durand et al. (2009) reported that temperatures in the French Alps are rising in the spring but falling in autumn. In particular, the late winter and early summer temperatures during recent years have remained high. Consequently, from 1850 to 1980 , retreating glaciers in the European Alps have lost approximately 30 to $40 \%$ of their surface area and approximately $50 \%$ of their original volume (Haeberli and Beniston, 1998). The climate models under the A1B scenario have projected a 2.2 to $5.1^{\circ} \mathrm{C}$ annual mean warming in the Alps by 2080-2099 compared to the annual average temperature in 1980-1999, concluding that changes in the hydrological cycle and associated ecosystems in the future may be more profound than ever (Liggins et al., 2010).

Even though climate changes had dramatic impacts during the 20th century in the Alpine region, the Tagliamento River in Italy, which is considered the last morphologically intact river in the Alps, has not suffered drastic modifications. However, because changes in the future climate are projected to be more intense, many concerns have been raised regarding the potential burden that may be imposed on hydrological processes in the Tagliamento valley. Thus, the objective of this study was to evaluate the potential climate change effects on the availability of future water resources in the Tagliamento River. The predictions of this study are expected to raise the concerns of policy makers, leading to the development of sustainable water management practices to cope with a changing climate.

\section{Methodology}

\subsection{Study area}

The Tagliamento River in northeastern Italy flows from the Italian Alps to the Adriatic Sea. The area of interest covers $1935 \mathrm{~km}^{2}$ for the Venzone water discharge measuring station, with elevations ranging from $370 \mathrm{~m}$ at the catchment outlet to $2600 \mathrm{~m}$ in the northeastern Alpine areas (Fig. 1a). The study area is covered with a dense weather station network, which includes 11 meteorological stations (approximately one station per $175 \mathrm{~km}^{2}$ ), with daily observations covering the past $31 \mathrm{yr}$ (1980-2010). The seasonal snow cover begins to accumulate in late November or early December, and snowmelt typically commences at the end of March or the beginning of April. Low river discharge generally occurs in the winter when most precipitation accumulates as snow. A sustained period of high flows prevails during the spring (late April to early June), resulting from the melting of the winter snowpack. The river discharge gradually declines from early summer, when the evapotranspiration demand is high and after snow disappears from the catchment. The onehour river discharges averaged daily from January 2008 to September 2009 were used for the analysis.

According to the meteorological records from 1980 to 2010, the annual average temperature near the catchment outlet was approximately $10.9^{\circ} \mathrm{C}$, and the temperature decreased with elevation at an average rate of $4.2^{\circ} \mathrm{C}$ per $1000 \mathrm{~m}$. The mean daily temperature remained below $0^{\circ} \mathrm{C}$ 


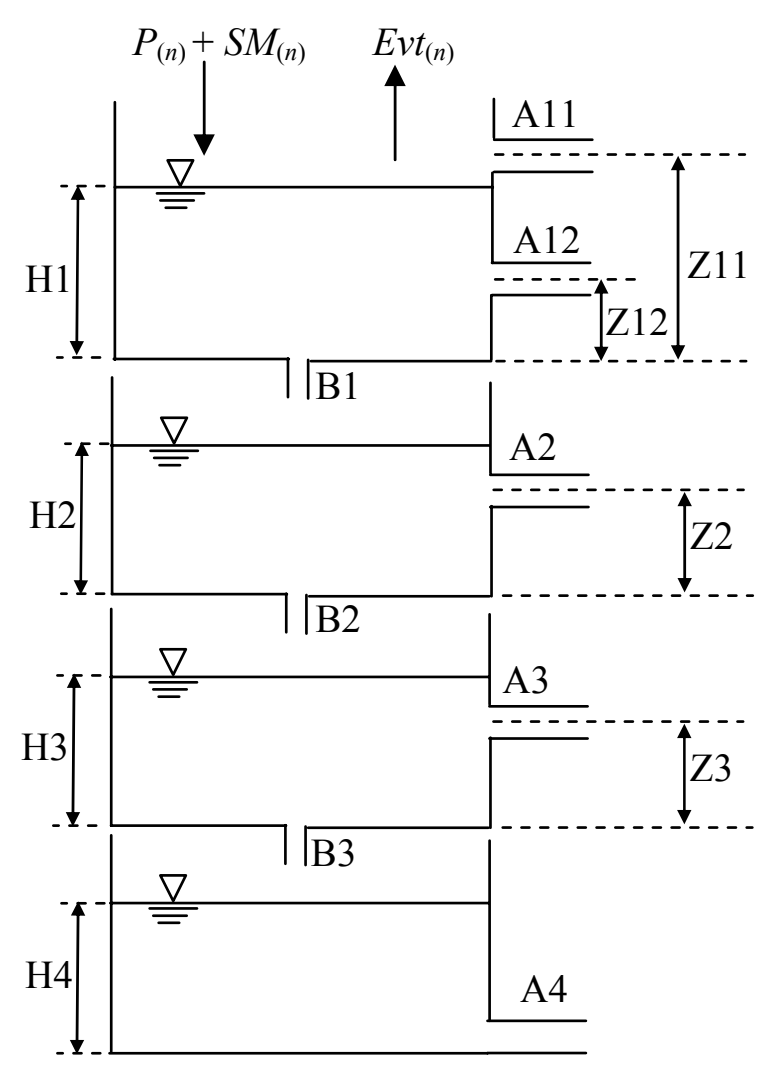

Fig. 2. Tank model structure for runoff estimations.

for an average of 21 days $\mathrm{yr}^{-1}$ near the catchment outlet, and for 36 days $\mathrm{yr}^{-1}$ upstream of the catchment (at Forni Avoltri station, at $888 \mathrm{~m}$ a.s.l.). The daily average winter (December-February) temperature was close to the melting point $\left(2.1\right.$ and $1.0^{\circ} \mathrm{C}$ near the catchment outlet and at Forni Avoltri station, respectively), which may adversely affect seasonal snow cover changes under a changing climate. When records from all meteorological stations were considered, warming trends were evident on decadal and longer time-scales. For example, during the 2000-2009 period, the average daily minimum temperature for all of the recording stations increased by $0.57-2.47^{\circ} \mathrm{C}$ in comparison to the average during 1980-1989. Similarly, the average daily maximum temperature over the 2000-2009 period increased by $0.09-1.8^{\circ} \mathrm{C}$ compared to the average for $1980-1989$. Both the maximum and minimum temperatures showed positive trends throughout all seasons. In particular, the temperature from late winter to early summer remained high.

The rate of increasing precipitation with elevation is unclear due to the effect of local topography on precipitation processes in mountainous climates. Therefore, the daily precipitation was averaged using the Thiessen polygon method (Zion et al., 2011). According to the annual precipitation from 2006 to 2010, two distinct pluvial zones can be identified: (1) the northern catchment area, with a mean annual precipitation ranging from 1500 to $1800 \mathrm{~mm}$, and (2) the
Alpine foreland area, with a mean annual precipitation ranging from 1900 to $2900 \mathrm{~mm}$. In general, the annual precipitation at all stations is increasing slightly $\left(0-24 \mathrm{~mm} \mathrm{yr}^{-1}\right)$, and snow precipitation trends follow the temperature change. Here we used frost day as an indicator for determining water resources impacts. Among various definitions, we considered the frost day as a day with an average temperature below $0^{\circ} \mathrm{C}$ (Salinger and Griffiths, 2001). As a result, the number of frost days during 1980-2010 decreased by approximately 10-13 days for each $1{ }^{\circ} \mathrm{C}$ of winter warming.

According to the land use percentages derived from Landsat imaging for 29 July 2002 (Fig. 1b), the land cover in the catchment is dominated by forest $(77 \%$ of the land area has an NDVI higher than 0.1). There is some agriculture, and to a lesser extent, some scattered developments are located along the river valley, which represent less than $12 \%$ of the total catchment area (areas with NDVI values from -0.1 to 0.1 ). The geology of the catchment area mainly consists of limestone and flysch, which is occasionally intermixed with layers of gypsum (Tockner et al., 2003).

\subsection{Model for river discharge simulation}

The tank model proposed by Sugawara (1995) is a lumpedparameter, non-linear, rainfall-runoff model composed of one or several tanks (Fig. 2). The coefficients used to represent different hydrological processes (surface and subsurface runoff and infiltration) are generally obtained by matching observed and simulated data. The difference in magnitude of these coefficients in different catchments reflects the geographical features of the watersheds. In addition to the use of the tank model in many studies for runoff simulations (e.g. Yokoo et al., 2001; Hashino et al., 2002, Cooper et al., 2007), similar concepts have been applied to water quality (Maeda and Bergstrom, 2000) and geothermal (Tureyen and Akyap, 2011) studies. In the simulation, glacier and snow-melt treated as a single water body, summed up with the rainfall and put in the first tank at the top (Kite, 1991). Evapotranspiration is directly subtracted from the top tank (Hashino et al., 2002). Among the four tanks in the model, the first tank at the top accounts for rapid runoff near the ground surface, and the second tank models the shallow subsurface runoff process. The other two tanks at the bottom retain the surplus water from the two top tanks before producing direct runoff. This phenomenon represents the hydrological role of deep aquifers, which accumulate the infiltrating water from the ground surface and release it downstream with certain time delays. A representative mathematical model for the water exchange between the tanks and daily runoff generation can be found in Appendix A.

A temperature-based method was applied to separate precipitation into rain and snow. If the daily minimum temperature $\left(T_{\min }\right)$ is larger than the threshold temperature $\left(2{ }^{\circ} \mathrm{C}\right.$ in this study), then all precipitation is considered as rain. If the maximum temperature $\left(T_{\max }\right)$ is smaller than the threshold 
temperature, then all precipitation is assumed to occur as snow. When the threshold temperature is between the minimum and maximum temperatures, the rainfall amount $\left(P_{\text {rain }}\right)$ is estimated as a proportion of the total precipitation $\left(P_{\text {total }}\right)$ as follows (Leavesley et al., 1983; Zion et al., 2011).

$$
P_{\text {rain }}=\frac{T_{\max }-2.0}{T_{\max }-T_{\min }} \times P_{\text {total }}
$$

The snow pack for the present day $\left(\right.$ Snow $\left._{d}\right)$ in the catchment was updated with the snow pack for the previous day $\left(\right.$ Snow $\left._{\mathrm{d}-1}\right)$, the snowfall for the present day $\left(P_{\text {snow }_{\mathrm{d}}}\right)$ and the snowmelt for the present day $\left(S_{\text {melt }_{\mathrm{d}}}\right)$ as follows.

Snow $_{\mathrm{d}}=$ Snow $_{\mathrm{d}-1}+P_{\text {snow }_{\mathrm{d}}-\mathrm{S}_{\text {melt }}}$

The snowmelt was assumed to be a function of the mean air temperature of the day $\left(T_{\text {avg }}\right)$ and was estimated using the degree-day method.

$S_{\text {melt }_{\mathrm{d}}}=K \times\left(T_{\text {avg }}-0\right)$ for $T_{\text {avg }}>0$

where $K$ is a calibrated melt coefficient and

$T_{\text {avg }}=\frac{T_{\min }+T_{\max }}{2}$

Only one parameter must be estimated, and thus, this method is simple to apply in climate change studies. Due to the higher level of uncertainties incorporated in the general circulation model (GCM) output (e.g. temperature, precipitation, humidity), the use of many climatic parameters for impact predictions eventually increases the uncertainty of the final output (Salathe et al., 2007). The Hargreaves equation (Hargreaves and Samani, 1985), which is one of the most widely used temperature-based formulas, was used to estimate the reference evapotranspiration $\left(\mathrm{ET}_{0}\right)$.

$\mathrm{ET}_{0}=\frac{0.0023}{\lambda}\left(\frac{T_{\max }+T_{\min }}{2}+17.8\right) \times \sqrt{T_{\max }-T_{\min }} \times R_{\mathrm{a}}$

where $R_{\mathrm{a}}\left(\mathrm{MJ} \mathrm{m}^{-2} \mathrm{~d}^{-1}\right)$ is the extra-terrestrial solar radiation and $\lambda$ is the latent heat of vaporization $\left(2.45 \mathrm{MJ} \mathrm{m}^{-2} \mathrm{~d}^{-1}\right)$.

\subsection{Remote sensing technique for identifing different snowfall-snowmelt elevation bands}

Elevation is an important parameter governing the snowfallsnowmelt processes in mountainous areas. Considering the $1700 \mathrm{~m}$ elevation difference between the catchment outlet and the northeastern crest and a temperature lapse rate (the rate of temperature decrease with elevation) of approximately $0.004^{\circ} \mathrm{C} \mathrm{m}^{-1}$, we can expect a temperature difference of approximately $7^{\circ} \mathrm{C}$ between the upstream and downstream catchment areas. Therefore, the spatial and temporal variations of the snowfall-snowmelt processes due to elevation are of prime importance for accurate river discharge simulations. Fontaine et al. (2002) incorporated the elevation difference effect in a semi-distributed hydrological model by introducing up to 10 elevation bands within each sub-basin. Zhang et al. (2008) showed that use of the elevation band method, including the temperature lapse rate in a catchment with a dense weather station network, provides discharge simulation almost as good as a complex energy budget model. In this study, the temporal and spatial variations of the glacier- and snow-covered areas in the basin were determined using satellite data. Landsat TM and ETM+ images obtained from 2001-2003 were selected at a $30 \mathrm{~m}$ grid resolution in such a way that the maximum cloud cover was always less than $15 \%$. To represent the temporal changes in snow cover, 15 Landsat images covering each season were collected. In the Landsat images, the glacier and snow spectral values are grouped as $255,145-255,191-$ 255, 116-217, 20-31 and 3-18 in bands (TMs) $1-5$ and 7 (Erdenetuya et al., 2006). In the initial stage, these spectral ranges were used as a reference for snow and glacier classification. For the next step, the band combination method was used to extract the snow and glacier areas. Three band combinations, 3,2,1;4,3,2; and 5,4,3 were compared with each other to identify areas with similar land classes. To distinguish glacier and snow from similarly bright soil, rocks and clouds, the normalized difference snow index (NDSI) was also applied (Eq. 11).

$\mathrm{NDSI}=\frac{(\mathrm{TM} 2-\mathrm{TM} 5)}{\mathrm{TM} 2+\mathrm{TM} 5}$

Altogether, 7 elevation bands with a maximum elevation difference of $300 \mathrm{~m}$ were identified. The average elevation of a particular band was multiplied by the temperature lapse rate to derive the representative temperature of the elevation band and further used to determine the snowfall percentage and snowmelt rate.

\subsection{Multi-model ensembles for climate projections}

The Intergovernmental Panel on Climate Change (IPCC) Fourth Assessment Report (AR4) provides a set of GCMs that are commonly used to assess the impacts of a changing climate. Although these models produce output for a common set of experiments, uncertainties in predictions arise from differences in grid resolutions, model structures and initial conditions. Therefore, reliable impact assessments require multi-model ensembles with several scenarios that best reflect a range of possible future climate change (Salathe et al., 2007). Nevertheless, the direct use of the GCM output is hampered by its coarse spatial resolution.

In this study, the results of four GCMs along with 3 scenarios, producing 10 climate change scenarios in three time periods (the short-term climate (2011-2030), the midterm climate (2046-2065) and the long-term climate (20802099)), were used (Table 1). The spatial mismatch between the GCMs and the resolution needed for impact assessment was resolved by applying a statistical downscaling technique. The stochastic weather generator (WG), which is commonly 
Table 1. Details of the GCMs and scenarios used in this study. The three time periods represent climate predictions in the short-term climate (2011-2030), the mid-term climate (2046-2065) and long-term climate (2080-2099).

\begin{tabular}{llllll}
\hline Model & Model acronym & Country & Grid resolution & Emissions scenarios & Time periods \\
\hline CSIRO-MK3.0 & CSMK3 & Australia & $1.9 \times 1.9^{\circ}$ & A1B, B1 & $2011-2030$, \\
MRI-CGCM2.3.2 & MIHR & Japan & $2.8 \times 2.8^{\circ}$ & A1B, B1 & $2046-2065$, \\
HadCM3 & HADCM3 & UK & $2.5 \times 3.75^{\circ}$ & A1B, A2, B1 & $2080-2099$ \\
PCM CCSM3 & NCCCS & USA & $1.4 \times 1.4^{\circ}$ & A1B, A2, B1 & \\
\hline
\end{tabular}

Details about GCMs and emission scenarios can be found in: http://www.cics.uvic.ca/scenarios/index.cgi?More_Info-Emissions.

used for downscaling, was used to link GCM model parameters with corresponding observations at the local scale (Semenov and Stratonovitch, 2010). Observed daily weather data for 1980-2010 were used in the WG model to determine probability distributions and any possible correlations. In this method, the cumulative probability distributions of dry and wet series, daily precipitation and minimum and maximum temperatures are defined by a semi-empirical distribution with 23 intervals. A wet day is defined as a day with precipitation $>0.0 \mathrm{~mm}$. When generating climate scenarios, the estimated cumulative probability function obtained from observations is adjusted by the relative change in magnitude of the corresponding parameter predicted by the future GCM scenario. Moreover, to determine whether the simulated data preserve statistical characteristics similar to those of the true long-term observations, model performances were assessed using the Chi-squared goodness-of-fit test, and the means and standard deviations were analyzed using t- and F-tests (detailed information can be found in Semenov and Stratonovitch, 2010).

\subsection{Low-flow analysis}

As recommended by the United States Environmental Protection Agency (USEPA), the 7Q10 low-flow index has been widely used to determine climate change impacts on river discharge (Kroll and Vogel, 2002; Matonse et al., 2011; Ryu et al., 2011). The USEPA (2009) defines 7Q10 flow as the lowest 7-day average discharge that occurs once every $10 \mathrm{yr}$. The probability distribution of the low-flow time series is approximated by the Log-Pearson type III distribution function (Reilly and Kroll, 2003; Ames, 2006). Three parameters are need for this distribution function, and they were estimated by fitting the natural logs of data to the Pearson type III distribution function (more details in Ames, 2006). Because the estimation from the 7Q10 method represents the minimum river discharge over a certain time period (generally longer than a decade), such analysis can provide useful information for long-term river basin management perspectives under changing climate conditions. Here, we developed lowflow statistics using the 1991-2010 period (baseline) and the short-term climate, mid-term climate and long-term climate time series.

\section{Results and discussion}

\subsection{Spatial and temporal changes in snow cover}

To understand the seasonal pattern of snow and glacier cover variation, Landsat images were analyzed using the band combination method and arithmetic operations of the NDSI index. Figure 3 depicts the discriminated glacier and snow area during intense snowfall (15 February) and snow-free (26 August) time periods. Snow and glacier areas mapped by the 5, 4, 3 band combination method are shown in light blue (Fig. 3b), and those for the NDSI-index-generated scenes are shown in white (Fig. 3a). The output from the band combination method and the NDSI index reveals that snowmelt begins in the low-elevation areas of the catchment, where, the snow cover is generally thin and the air temperature is high. Subsequently, as the temperature increases from winter to summer, the melt continues to the upper part of the catchment. Figure 4 a shows the temporal changes in snow cover for the study area. The seasonal snow cover tends to disappear at a faster rate during warmer climatic conditions (March-June), followed by a slow depletion under a colder temperature regime (December-February). It was estimated that, on average, approximately $46 \%$ of the basin is covered with snow and glacier from December to February, which decreases to less than $5 \%$ for July to September. According to Fig. 4b, the snow cover change follows the trend of temperature variation in the catchment. Once the air temperature passes the $0{ }^{\circ} \mathrm{C}$ threshold, the snow cover area begins to be depleted at a rate of $15157 \times \exp ^{-0.32(T e a m)}$, which is almost constant until the end of May. The substantial melting rate of winter snowpack during this period contributes to a sustained period of high river flows during the spring and early summer.

Figure 5 depicts the observed and simulated river discharges at the Venzone gauge station. The simulated water discharges are in agreement with the corresponding observations, with a Nash-Sutcliff coefficient greater than 0.75 . According to Fig. 5, comparatively higher river flow can be observed during spring (March-May). The total river discharge in this period accounted for approximately $25 \%$ of the annual river discharge. However, the precipitation in this period is comparatively small, contributing less than $12 \%$ of 
a) August-26

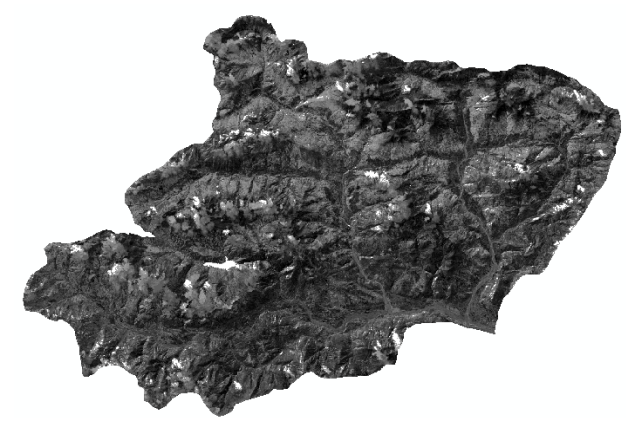

b) February-15

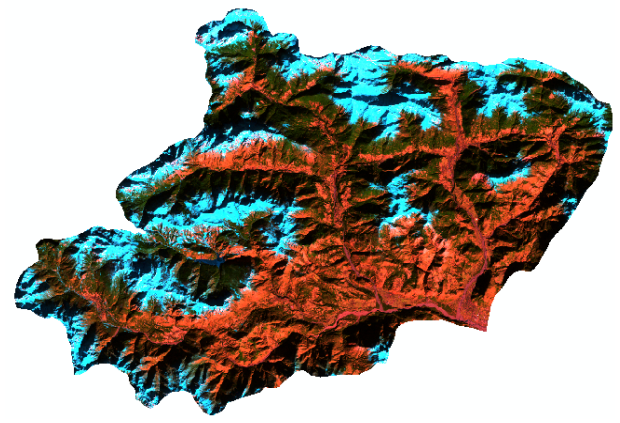

Fig. 3. Glacier and snow cover area during two time periods; (a) from band combination method and (b) from NDSI index.

a)

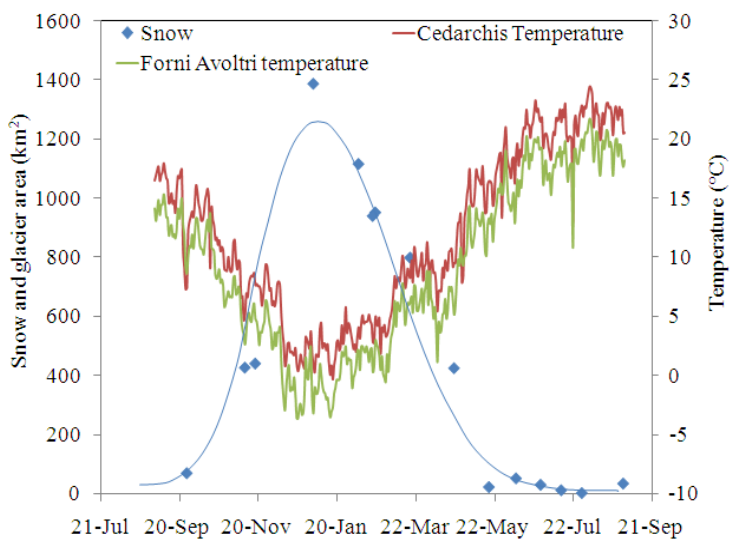

b)

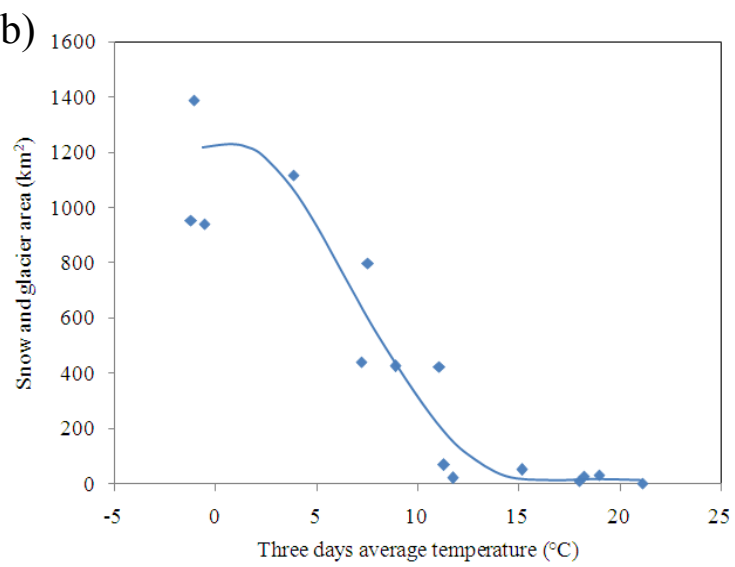

Fig. 4. (a) Temporal changes in snow and glacier cover. (b) Variations in snow and glacier cover with respect to the three-day mean temperature averaged for all meteorological stations.

the annual precipitation. As a result, according to our simulations, approximately $53 \%$ of the river discharge during the spring season is generated by snowmelt.

\subsection{Precipitation, snowfall and air temperature under a changing climate}

To assess the temporal variations resulting from a changing climate, the relative changes in climate parameters for three future time periods were compared with those of the baseline period. Figure 6 shows the changes in the monthly average maximum and minimum temperatures at the Forni Avoltri meteorological station, which is $888 \mathrm{~m}$ a.s.l. (Fig. 1). Based on 10 model scenarios, the annual mean warming from the baseline climate for the short-term climate varies from -0.3 to $0.3^{\circ} \mathrm{C}$ and from -0.1 to $0.6^{\circ} \mathrm{C}$, with an average of 0.1 and $0.3^{\circ} \mathrm{C}$ for the minimum and maximum temperatures, respectively. However, the magnitude of warming significantly increases for the later time periods. For example, the annual mean warming averaged over 10 scenarios for the longterm climate is as high as $2.3^{\circ} \mathrm{C}\left(0.6\right.$ to $\left.3.7^{\circ} \mathrm{C}\right)$ for the mini-

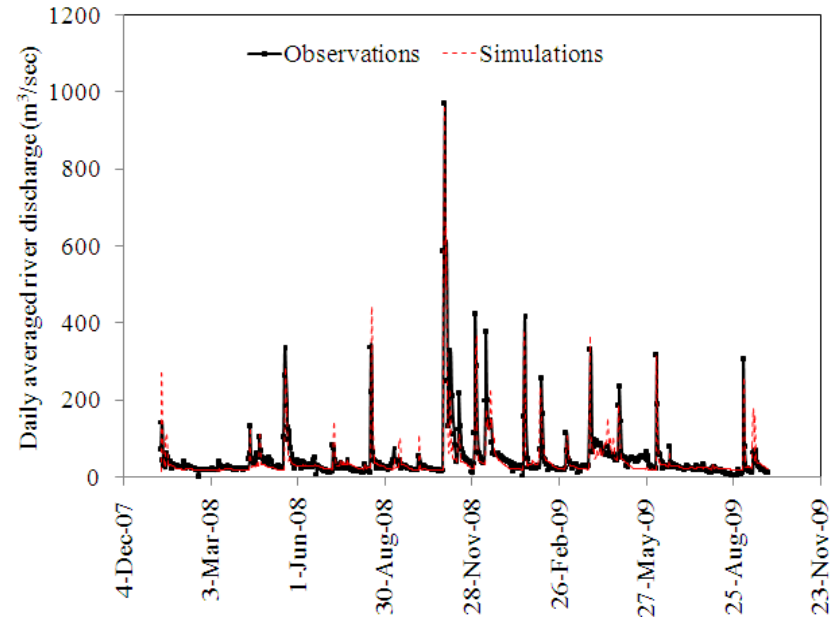

Fig. 5. Observed and simulated daily averaged river discharge at the Venzone station. 

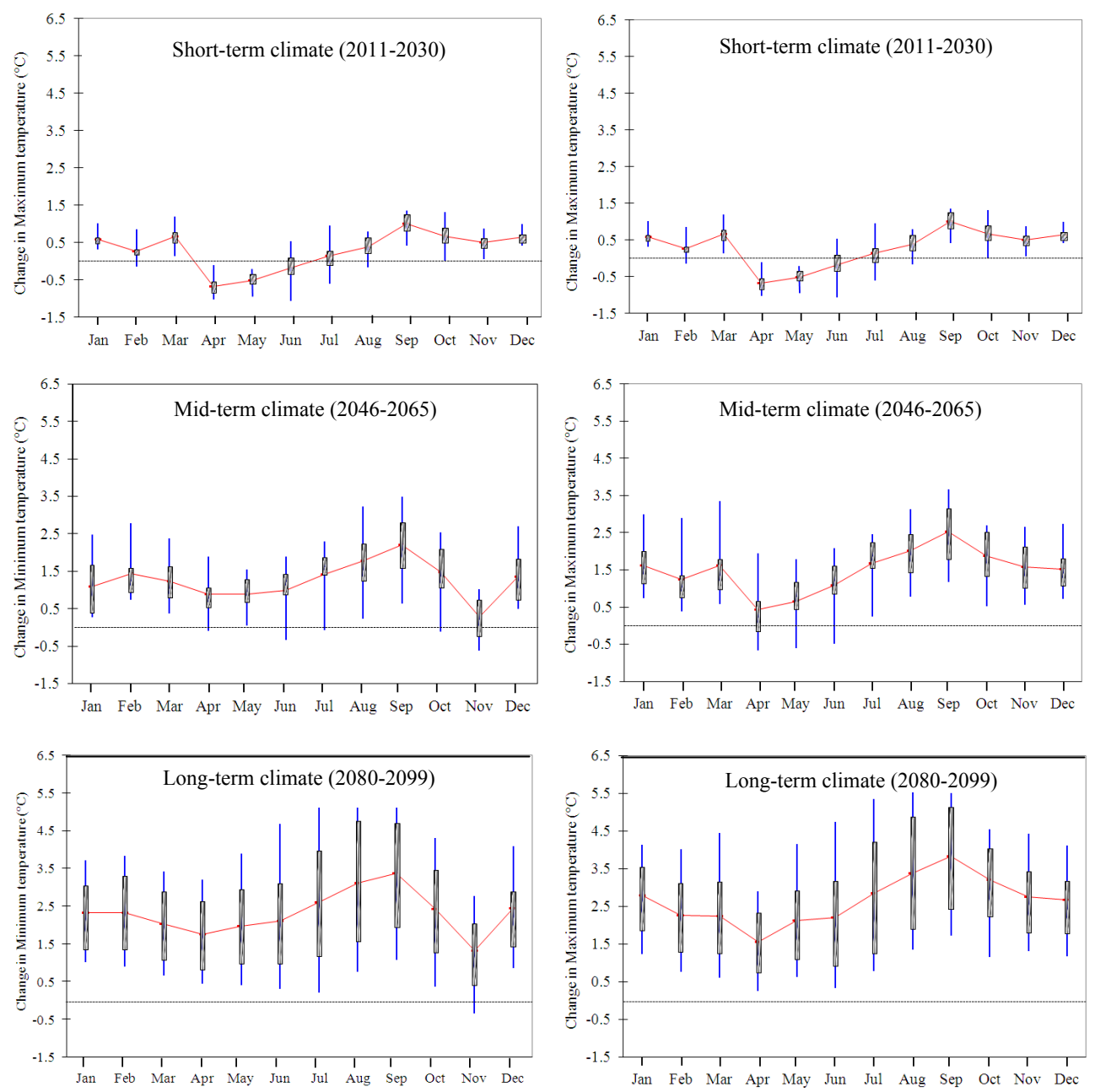

Fig. 6. The change in monthly average minimum and maximum temperatures compared to temperatures of the baseline time period. The box-plots represent the interquartile range for the 25 th and 75 th percentiles from all 10 scenarios. The solid line represents the average of 10 scenarios.

mum temperature and $2.7^{\circ} \mathrm{C}\left(1.0\right.$ to $\left.4.0^{\circ} \mathrm{C}\right)$ for the maximum temperature.

When seasonal changes in temperature are considered, all model scenarios show a generally similar trend of warming for the three time periods. The warming from the middle of summer to the middle of autumn (June-October) is always higher and more persistent than in the other months for all three future time periods. These results are consistent with the findings of the earlier project (STARDEX, 2002), which reported the potential for strong temperature increase in summer in Northern Italy. The most consistent and greatest warming occurs in September, when the HADCM3-A2 scenario predicts a warming of $1.1-5.2^{\circ} \mathrm{C}$ for the minimum temperature and $1.7-5.5^{\circ} \mathrm{C}$ for the maximum temperature for the long-term climate compared to the baseline time period. On average, the winter temperature increases from 1.0 to $3.8^{\circ} \mathrm{C}$ for the minimum temperature and from 1.2 to $4.1^{\circ} \mathrm{C}$ for the maximum temperature for the long-term climate compared to the baseline time period. This persistent increase in winter temperature could significantly reduce the snowfall amount. For example, the average number of frost days per year (days with an average temperature below $0{ }^{\circ} \mathrm{C}$ ) ranges from approximately 18 downstream (Cedarchis meteorological station (Fig. 1), at approximately $402 \mathrm{~m}$ a.s.1.) to approximately 52 upstream of the study area (Forni Avoltri meteorological station, at approximately $888 \mathrm{~m}$ a.s.l.) during the baseline time period. According to the averaged predictions from 10 scenarios, for a $2.5^{\circ} \mathrm{C}$ increase in winter temperature at the Forni Avoltri meteorological station, the number of frost days is likely to decrease by 35 days. In lower elevations, the reduction is expected to increase by more than the amount estimated for higher-elevation areas. For example, Fig. 7 shows the change in the number of frost days with winter temperature as predicted by $10 \mathrm{GCM}$ scenarios from the baseline and the three future time periods. According to these results, the number of frost days decreases exponentially as the 
a)

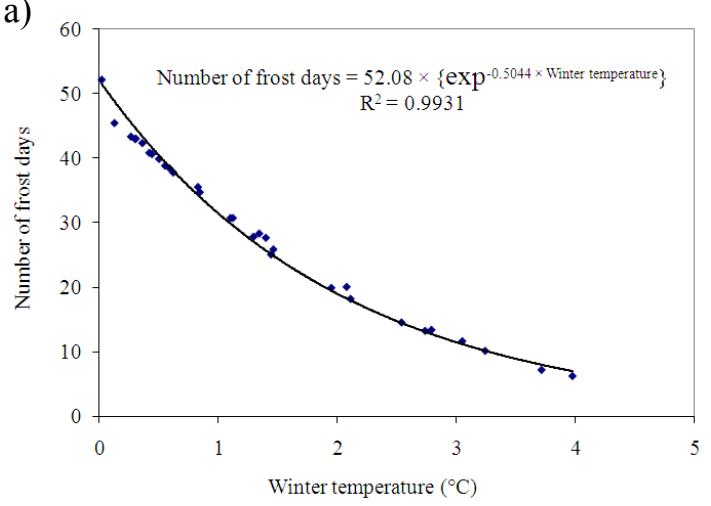

b)

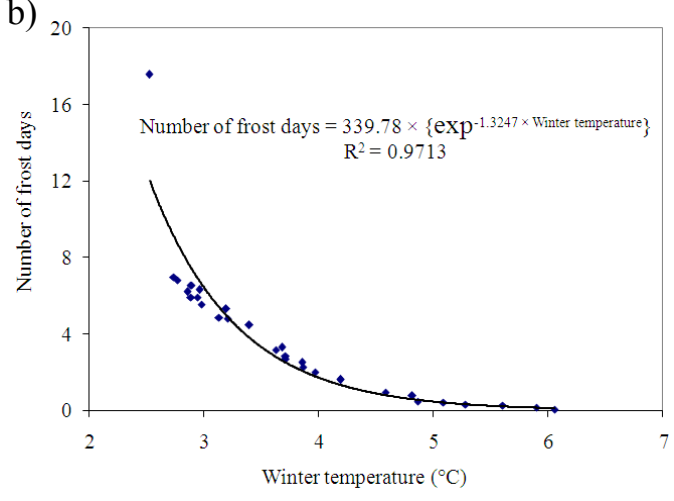

Fig. 7. The change in number of frost days with daily average winter temperature (a) at the Forni Avoltri station and (b) at the Cedarchis station. Each data point in the graph represents the number of frost days predicted by a certain scenario within a certain time period.
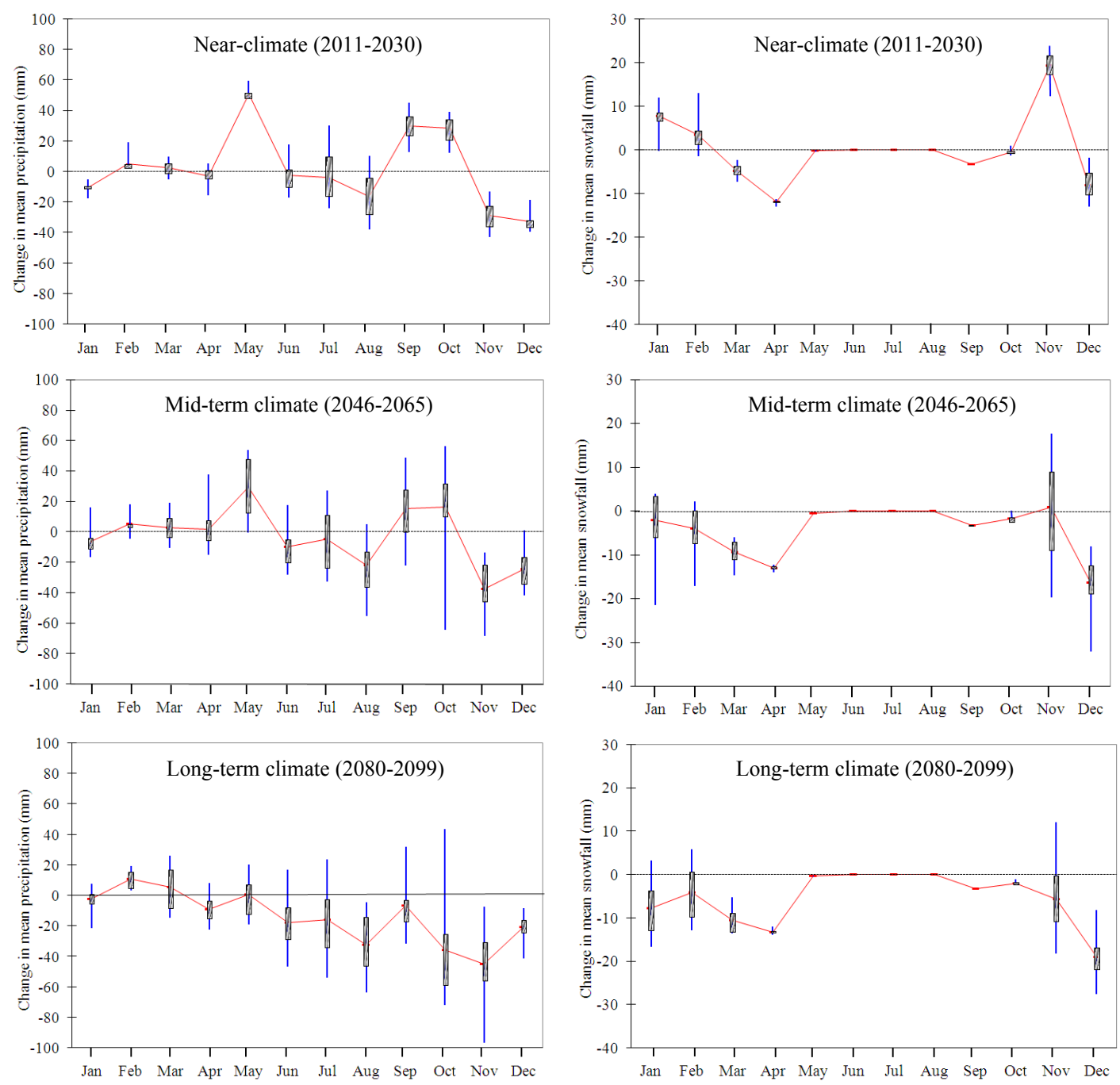

Fig. 8. Change in monthly precipitation and snowfall compared to the baseline time period. The box-plots represent interquartile ranges for the 25 th and 75 th percentiles from all 10 scenarios. The solid line represents the average of 10 scenarios. 

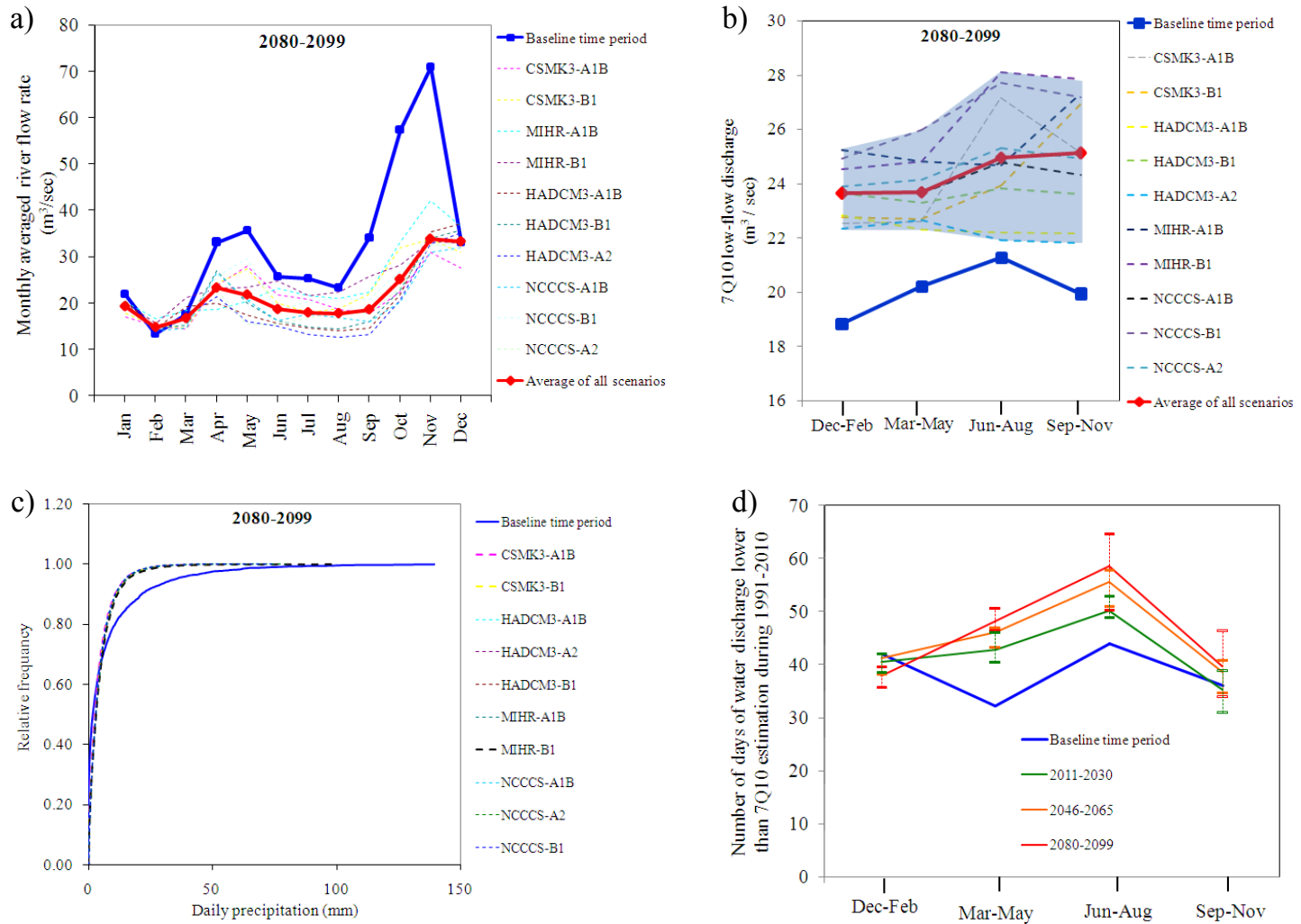

Fig. 9. Results of river discharge predictions for the long-term climate. (a) Changes in monthly average river discharge compared to the baseline time period. (b) 7Q10 low-flow discharge compared to the baseline time period. (c) Relative frequency of daily precipitation compared to the baseline time period. (d) Number of days with river water discharge lower than the 7Q10 estimation for the baseline time period. The whiskers represent the interquartile range for the 25 th and 75 th percentiles from all 10 scenarios. The solid line represents the average of 10 scenarios.

winter temperature increases. Notably, the rate of frost day decrease in the lower-elevation area (Cedarchis area, with a 1.32 rate) is $262 \%$ higher than that in the higher-elevation area (Forni Avoltri area, with a 0.50 rate). Consequently, the daily average temperature in the lower-elevation area may only rarely fall below $0{ }^{\circ} \mathrm{C}$ during the 2080-2099 time period, which in turn will have serious effects on snowfall and snow cover melt.

Changes in the precipitation patterns with respect to magnitude and phase (snow or rain) may have an even greater impact than surface air temperature warming on the hydrological processes of a river basin. According to Fig. 8, the annual mean precipitation (rainfall + snowfall) change from the baseline time period to the short-term climate is $-1.8 \%$ to $3.3 \%$, with only a minor change when averaging all model scenarios $(0.6 \%)$. However, the mid-term climate predictions depict a modest change in the annual mean precipitation $(-12.2 \%$ to $4.5 \%$ change compared to the baseline period), and by the end of the 21 st century (long-term-climate), the corresponding changes become significant $(-17.4 \%$ to $1.7 \%$ change compared to the baseline period average).
Almost all of the models and scenarios analyzed (90\%) show a decrease in winter precipitation for all time periods. Despite the increasing winter precipitation in some months (e.g. February), a significant reduction in snowfall can be expected due to warmer winter temperatures. For example, for $1.1-4.0^{\circ} \mathrm{C}$ winter warming in the long-term climate, snowfall will likely decrease by $48-67 \%$ compared to that in the baseline time period. The modest increase in the mean monthly precipitation during May (40\%), September (23\%) and October $(17 \%)$ in the short-term climate gradually declines by $50 \%$ for the mid-term climate $(24 \%, 12 \%$ and $10 \%$ for May, September and October, respectively) and is further reduced to a negative change in the long-term climate $(0.6 \%$, $-5 \%$ and $-22 \%$ for May, September and October, respectively). Similarly, for all other months, the magnitude of the monthly mean precipitation change decreases with time from the present climate until end of the 21 st century.

\subsection{Future river discharge predictions and the results of low-flow analysis}

The warming climate projected by the 10 scenarios will enhance the evapotranspiration rate and the proportion of liquid 


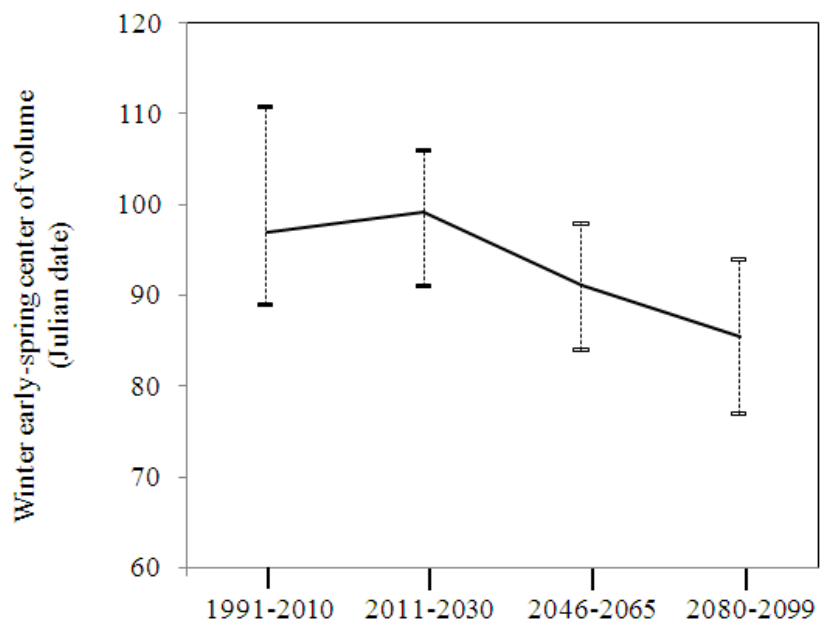

Fig. 10. Shift in river discharge timing in the future compared to baseline climate conditions. The whiskers represent the interquartile range for the 25th and 75th percentiles from all 10 scenarios. The solid line represents the average of 10 scenarios.

to solid precipitation. These potential changes in precipitation amount and seasonality demonstrate that the accumulated impact of climate change may have serious consequences on water availability in the Tagliamento River. The seasonal change in river discharge is significant for all months in all three future time periods except from winter to early spring (December-March). In general, the reductions in river discharge are comparatively small in the shortterm climate but become significant in the long-term climate conditions. Figure 5a shows the change in daily average monthly discharge as predicted by 10 scenarios in comparison with the discharge for the baseline time period. River discharge is predicted to drop significantly during the autumn season (September-November), which is mainly attributed to the predicted warming and precipitation reduction in the future climate (representing the highest changes in comparison to the other seasons, as shown in Figs. 6 and 8). For example, the highest reduction will occur in October, with a value approximately $59 \%$ lower than the river discharge in the baseline climate. In spite of the significant temperature increase (but smaller precipitation change), the winter river discharge remains almost constant for all future time periods, mainly because more precipitation will occur as rain rather than snow and because snowmelt will start earlier due to a warming climate.

According to the low-flow analysis results (Fig. 9b), the magnitude of the 7Q10 discharge will clearly increase for all scenarios (e.g. a $25 \%$ increase on averaged over 10 scenarios during the winter season). This behavior contradicts the expected decline in river discharge due to an increase in evapotranspiration demand and a precipitation drop in the future, but can be explained by the relative frequency distribution of daily precipitation in the future compared to the baseline time period. As shown in Fig. 9c, on average, predictions from the different scenarios indicate an increased frequency of low precipitation events in the future compared to the baseline time period. For example, the relative frequency of daily precipitations less than $15 \mathrm{~mm}$ increases from $85 \%$ for the baseline time period to $93-95 \%$ for the long-term climate. On the other hand, the daily precipitation corresponds to a 99th percentile value decrease from $72.2 \mathrm{~mm}$ for the baseline time period to $25.5-30.2 \mathrm{~mm}$ for the long-term climate. Therefore, on a broader time scale (an average of 2 decades in this study), we can expect regular low-level river discharge in the future compared to the present climate. Figure $9 \mathrm{~d}$ shows the seasonal change in low-flow events compared to 7Q10 estimations for the baseline time period. While the predicted low-flow events during autumn and winter remain relatively unchanged, a significant increase in low-flow events can be observed for the spring and summer seasons, which further intensify from the short-term climate to the long-term climate by the end of the 21 st century. For example, the annual low-flow events, on average, will increase by 16 and 15 days during the spring and summer seasons, respectively, in the long-term climate in comparison to the average for the baseline period. Therefore, according to the results shown in Fig. $9 \mathrm{~b}$ and d, we can conclude that, even though the magnitude of the minimum river discharge increases under the changing climate, variations in water discharge can increase significantly, leading to a future with regular low-flow events.

\subsection{Shift in river discharge timing attributed to earlier snowmelt}

Because much of the spring river discharge is produced by snowmelt $(53 \%$ according to the simulation results shown in Fig. 5), a shift in river discharge timing is a clear indicator for investigating climate change impacts in mountainous climates. For this study, the winter-early spring center of volume, which is defined as the Julian Day when half of the total river discharge from January to May has occurred (WSCV), was used to evaluate the river discharge timing for the baseline and future time periods (Zion et al., 2011; Hodgkins and Dudley, 2006). Figure 10 depicts the change in WSCV from the baseline climate to the end of the 21 st century. On average, the results from 10 scenarios indicate a slight delay in the WSCV date in the short-term climate due to the predicted increase in snowfall in January and February (Fig. 8) and no significant change in temperatures compared to the baseline climate. In contrast, for the mid-term climate and long-term climate, a significant change in river discharge timing can be expected, which according to the average of all GCM scenarios studied, may shift the timing of river discharge to occur 6 to 12 days earlier than in the baseline climate. This shift in WSCV represents an integrated response of the catchment to the significant variations in temperature and precipitation during the mid-term climate and long-term climate (Figs. 6-8). 


\section{Conclusions}

The European Alps are a mountain range subject to the dominant influence of climate change. Thus far, the Tagliamento River in Italy has not experienced drastic modifications but is likely to be vulnerable to a changing climate. This study therefore used 10 GCM scenarios for three future time periods to evaluate the hydrological response of the Tagliamento River for probable variations in temperature and precipitation patterns.

The snow and glacier areas mapped by the Landsat images indicate that $46 \%$ of the catchment area is generally occupied by snow cover during the winter and that the snow cover starts to disappear from low-elevation areas to the top of the catchment at a rate of $15157 \times \exp ^{-0.32(\text { Team) }}$. The winter temperature in the study area is close to the melting point $\left(2.1\right.$ and $1.0^{\circ} \mathrm{C}$ near the catchment outlet and in highelevation areas, respectively), and thus, the natural states of snowfall and snowmelt processes are more vulnerable under a changing climate. When all GCM model scenarios were taken in to account, a consistent warming trend was observed, beginnings with a relatively minor change in the short-term climate $\left(0.1\right.$ and $0.3{ }^{\circ} \mathrm{C}$ when averaging all scenarios for the minimum and maximum temperatures, respectively, for 2011-2030) and becoming as large as 2.3 (0.6$\left.3.7^{\circ} \mathrm{C}\right)$ and $2.7^{\circ} \mathrm{C}\left(1.0-4.0^{\circ} \mathrm{C}\right)$ for the minimum and maximum temperatures, respectively, by 2080-2099 compared to the baseline climate (1991-2010). Notably, the warming rate during the winter and autumn seasons will always be high and persistent, thereby hampering the cold environment needed for snowfall. In terms of snowfall, much larger changes can be expected in low-elevation areas than in highelevation areas. For example, the exponential rate of frost day decrease for $1{ }^{\circ} \mathrm{C}$ winter warming at lower-elevation areas is approximately three-fold (262\%) higher than that in higher-elevation areas. As such, snowfall in higher-elevation areas will decrease by $48-67 \%$ by the end of the 21 st century (2080-2099) compared to the baseline climate, but the lower elevations are more likely to go without significant snowfall (a 79-100\% decrease compared to the baseline climate).

Despite the fact that $90 \%$ of the scenarios predicted a decrease in winter precipitation, the river discharge will remain relatively unchanged for the winter months until the end of the 21st century due to an enhanced hydrological cycle caused by the warming climate. Consequently, the river discharge for all other months will decrease with the highest predicted reduction as large as 59\% in October for the 2080-2099 period compared to the baseline river discharge. The low-flow analysis indicated that the magnitude of the minimum river discharge will likely increase (e.g. a $25 \%$ increase in the lowest 7-day average river discharge with a 10yr return period during the winter season in the 2080-2099 time period compared to the baseline time period), which is attributed to the early snowmelt and an increased frequency of low precipitation events. Meanwhile, the annual low-flow events, on average, will increase by 16 and 15 days during the spring and summer seasons in the 2080-2099 time period, respectively, compared to the average for the baseline period. These results reveal that in addition to the decrease in river discharge volume over 9 months of the year, variations in river discharge may cause an uneven temporal distribution of the water in downstream areas. Moreover, a consistent shift in river discharge timing would eventually result in snowmelt-generated river discharge occurring approximately 12 days earlier during the 2080-2099 time period in comparison to the baseline climate. Such changes may cause the reservoir systems downstream to fill and release water earlier than usual, leading to a water shortage during the summer for water supply and agricultural purposes (Matonse et al., 2011).

In addition to the direct and indirect impacts on socioeconomic sectors such as agriculture, industry, hydropower and tourism, the long-term impacts on the natural environment could be significant. The decrease in snow cover duration and the warming climate may produce an increase in the length of the vegetative season, resulting in more water lost to transpiration. From an ecological point of view, mountain trees and animal species may shift to higher-elevation areas (Parry et al., 2007; Sandvik et al., 2004). As such, the impact level may vary from genetic adaptation to habitat and species diversity to, in an extreme case, species extinction. Moreover, increasing air temperatures and early snowmelt may increase the water temperatures in streams, lakes and wetlands and may have a dramatic effect on the ecological balance of these ecosystems. Water temperatures in surface ecosystems are highly sensitive to surface air temperature changes and may exceed the upper thermal limits of some species in the summer without adequate cool water supplies from groundwater discharge (groundwater is generally cooler than surface water in warmer months) and river water supplies (Gunawardhana et al., 2011). Therefore, the combined effects of surface air temperature changes (a $0.4-5.0^{\circ} \mathrm{C}$ change during summer in the 2080-2099 time period compared to the baseline time period), early snowmelt, regular low-flow conditions and increased variations in river water discharge may be problematic for the protection of aquatic ecosystems under a changing climate.

Finally, it is worth noting that our results are capable of addressing only the long-term trends of climate and associated hydrological regimes with certain levels of uncertainty because, in addition to the temperature and precipitation, changes in other climate parameters, such as solar radiation, relative humidity and wind speed, are important for snowmelt estimations. However, the data availability for mountainous regions over long periods of time is a major constraint in using detailed energy balance models for climate change studies. Furthermore, the use of many GCM parameters may eventually increase the uncertainty of the final output (Salathe et al., 2007). Moreover, the range of the predicted impact is dependent on the number of GCM 
scenarios used for the analysis and on their performances in capturing the local-scale climate. In particular, the GCM precipitation incorporates a high level of uncertainty when compared with local-scale precipitations in mountainous areas. Therefore, it is preferable to consider a range of models and scenarios instead of relying on a single forecast. The dense weather station network combined with the 10 GCM scenarios selected in this study is expected to simulate the future climate at the local scale with reasonable accuracy. Therefore, our results will be applicable for developing new water management strategies in the Tagliamento River basin under changing climate conditions.

\section{Appendix A}

The mathematical model for the water exchange between the tanks and daily runoff generation

$$
\begin{aligned}
& R_{x, n}= \begin{cases}A_{(x)} \times\left[H_{(x, n)}-Z_{(x)}\right] & H_{(x, n)}>Z_{(x)} \\
0 & H_{(x, n)} \leq Z_{(x)}\end{cases} \\
& I_{(x, n)}=B_{(x)} \times H_{(x, n)} \\
& H_{(x, n+1)}\left\{\begin{array}{l}
H_{(x, n)}-\left[R_{(x, n)} \times \Delta t\right]-\left[I_{(x, n)} \times \Delta t\right] \\
H_{(x, n)}-\left[R_{(x, n)} \times \Delta t\right]-\left[I_{(x, n)} \times \Delta t\right]
\end{array}\right. \\
& +\left[T_{(n+1)} \times \Delta t\right] x=1 \\
& +\left[I_{(x-1, n)} \times \Delta t\right] x \neq 1 \\
& T_{(n)}=P_{(n)}+\mathrm{SM}_{(n)}-\operatorname{Evt}_{(n)} \\
& Q_{(n)}=\sum_{x=1}^{4} R_{(x, n)}
\end{aligned}
$$

where

$x$ : number of tanks counted from the top

$n: \quad$ number of days from the beginning (1/d)

$\Delta t: \quad$ length of the time step

$A_{(x)}$ : runoff coefficient of the $x$ th tank (1/d)

$B_{(x)}$ : infiltration coefficient of the $x$ th tank (1/d)

$H_{(x, n)}$ : water depth in the $x$ th tank on the $n$th day (mm)

$Z_{(x)}$ : height of the runoff hole of the $x$ th tank (mm)

$R_{(x, n)}: \quad$ runoff from the $x$ th tank on $n$th day $\left(\mathrm{mm} \mathrm{d}^{-1}\right)$

$I_{(x, n)}: \quad$ infiltration in the $x$ th tank on the $n$th day $\left(\mathrm{mm} \mathrm{d}^{-1}\right)$

$T_{(n)}: \quad$ total input to the first tank on the $n$th day $\left(\mathrm{mm} \mathrm{d}^{-1}\right)$

$P_{(n)}: \quad$ precipitation on the $n$th day $\left(\mathrm{mm} \mathrm{d}^{-1}\right)$

$\mathrm{SM}_{(n)}$ : $\quad$ snow-melt on the $n$th day $\left(\mathrm{mm} \mathrm{d}^{-1}\right)$

$\operatorname{Evt}_{(n)}: \quad$ evapotranspiration on the $n$th day $\left(\mathrm{mm} \mathrm{d}^{-1}\right)$

$Q_{(n)}: \quad$ total runoff on the $n$th day $\left(\mathrm{mm} \mathrm{d}^{-1}\right)$
Acknowledgements. This research was partially supported by the Ministry of Education, Science, Sports and Culture, Grant-in-Aid for Scientific Research (B), 2010-2013 (22360192, So Kazama), and the Ministry of Education, Science, Sports and Culture, Grant-in-Aid for Scientific Research (A), 2010-2013 (21254003, Yasuhiro Takemon).

Edited by: E. Todini

\section{References}

Ames, D. P.: Estimating 7Q10 confidence limits from data: A Bootstrap approach, J. Water Res. Pl-ASCE, 132, 204-208, 2006.

Beniston, M.: Environmental Change in Mountains and Uplands, Arnold/Hodder Publishers, London, UK, and Oxford University Press, New York, USA, 2000.

Beniston, M.: Climatic change in mountain regions: A review of possible impacts, Climatic Change, 59, 5-31, 2003.

Beniston, M.: Mountain climates and climatic change: An overview of processes focusing on the European Alps, Pure Appl. Geophys, 162, 1587-1606, 2005.

Beniston, M., Keller, F., and Goyette, S.: Snow pack in the Swiss Alps under changing climatic conditions: an empirical approach for climate impacts studies, Theor. Appl. Climatol., 74, 19-31, 2003.

Cooper, V. A., Nguyen, V. T. V., and Nicell, J. A.: Calibration of conceptual rainfall-runoff models using global optimisation methods with hydrologic process-based parameter constraints, J. Hydrol. 334, 455-466, 2007.

Diaz, H. F. and Bradley, R. S.: Temperature Variations during the Last Century at High Elevation Sites, Climatic Change, 36, 253279, 1997.

Durand, Y., Laternser, M., Giraud, G., Etchevers, P., Lesaffre, B., and Merindol, L.: Reanalysis of $44 \mathrm{Yr}$ of Climate in the French Alps (1958-2002): Methodology, Model Validation, Climatology, and Trends for Air Temperature and Precipitation, J. Appl. Meteor. Climatol., 48, 429-449, 2009.

EEA: Regional climate change and adaptation: The Alps facing the challenge of changing water resources, Copenhagen, Denmark, doi:10.2800/12552, 2009.

Erdenetuya, M., Khishigsuren, P., Davaa, G., Otgontogs, M.: Glacier change estimation using Landsat TM data, International Archives of the Photogrammetry, Remote Sensing and Spatial Information Science, 36, 240-243, 2006.

Fontaine, T., A., Cruickshank, T. S., Arnold, J. G., and Hotchkiss, R. H.: Development of a snowfall-snowmelt routine for mountainous terrain for the soil water assessment tool (SWAT), J. Hydrol., 262, 209-223, 2002.

Gunawardhana, L. N., Kazama, S., and Kawagoe, S.: Impact of urbanization and climate change on aquifer thermal regimes, Water Resour. Manage., 25, 3247-3276, 2011.

Haeberli, W. and Beniston, M.: Climate Change and its Impacts on Glaciers and Permafrost in the Alps, Ambio, 27, 258-265, 1998.

Hargreaves, G. H. and Samani, Z. A.: Reference crop evapotranspiration from temperature, Appl. Eng. Agric., 1, 96-99, 1985.

Hashino, M., Huaxia, Y., and Yoshida, H.: Studies and evaluations on interception processes during rainfall based on a tank model, J. Hydrol., 255, 1-11, 2002. 
Hodgkins, G. A. and Dudley, R. W.: Changes in the timing of winter-spring streamflows in eastern North America, Geophys. Res. Lett., 33, L06402, doi:10.1029/2005GL025593, 2006.

Kawagoe, S., Kazama, S., and Sarukkalige, P. R.: Assessment of snowmelt triggered landslide hazard and risk in Japan, Cold Reg. Sci. Technol., 58, 120-129, 2009.

Kite, G. W.: A watershed model using satellite data applied to a mountain basin in Canada, J. Hydrol., 128, 157-169, 1991.

Kroll, C. N. and Vogel, R. M.: Probability distribution of low streamflow series in the United States, J. Hydrol. Eng., 7, 137146, 2002.

Leavesley, G. H., Lichty, R. W., Troutman, B. M., and Saindon, L. G.: Precipitation-Runoff Modeling System: User's Manual, Water Resources Investigations Report 83-4238, US Geological Survey, Denver, Colorado, 1983.

Liggins, F., Betts, R. A., and Mcguire, B.: Projected future climate changes in the context of geological and geomorphological hazards, Phil. Trans. R. Soc. A, 368, 2347-2367, 2010.

Maeda, M. and Bergstrom, L. F.: Leaching patterns of heavy metals and nitrogen evaluated with a modified tanks-in-series model, J. Contam. Hydrol., 43, 165-185, 2000.

Matonse, A. H., Pierson, D. C., Frei, A., Zion, M. S., Schneiderman, E. M., Anandhi, A., Mukundan, R., and Pradhanang, S. M.: Effects of changes in snow pattern and the timing of runoff on NYC water supply system, Hydrol. Process., 25, 3278-3288, 2011.

Miller, N. L., Bashford, K. E., and Strem, E.: Potential impacts of climate change on California hydrology, J. Am. Water Resour. As., 39, 771-784, 2003.

Parry, M., Canziani, O., Palutikof, J., Linden, P. V., and Hanson, C.: Climate change 2007: Impacts, Adaptation and Vulnerability. Summary for policymakers, Cambridge University Press, New York, 2007.

Reilly, C. F. and Kroll, C. N.: Estimation of 7-day, 10-year lowstreamflow statistics using baseflow correlation, Water Resour. Res., 39, 1236, doi:10.1029/2002WR001740, 2003.

Ryu, J. H., Lee, J. H., Jeong, S., Park, S. K., and Han, K.: The impacts of climate change on local hydrology and low flow frequency in the Geum River Basin, Korea, Hydrol. Process., 25, 3437-3447, 2011.

Salathe, E. P. Jr., Mote, P. W., and Wiley, M. W.: Review of scenario selection and downscaling methods for the assessment of climate change impacts on hydrology in the United States Pacific Northwest, Int. J. Climatol., 27, 1611-1621, 2007.

Salinger, M. J. and Griffiths, G. M.: Trends in New Zealand daily temperature and rainfall extremes, Int. J. Climatol., 21, 14371452, 2001.

Sandvik, S. M., Heegaard, E., Elven, R., and Vandvik, V.: Responses of alpine snowbed vegetation to long-term experimental warming, Ecoscience, 11, 150-159, 2004.
Schaefli, B., Hingray, B., and Musy, A.: Climate change and hydropower production in the Swiss Alps: quantification of potential impacts and related modelling uncertainties, Hydrol. Earth Syst. Sci., 11, 1191-1205, doi:10.5194/hess-11-11912007, 2007.

Schneeberger, C., Blatter, H., Abe-Ouchi, A., and Wild, M.: Modelling changes in the mass balance of glaciers of the northern hemisphere for a transient $2 \times \mathrm{CO}_{2}$ scenario, J. Hydrol., 282, 145-163, 2003.

Semenov, M. A. and Stratonovitch, P.: Use of multi-model ensembles from climate models for assessment of climate change impacts, Climate Res., 41, 1-14, 2010.

STARDEX: Statistical and regional dynamical downscaling of extremes for European regions, available at: http://www.cru.uea. ac.uk/projects/stardex/reports/STARDEX_FINAL_REPORT.pdf (last access date: 7 March 2012), 2002.

Stewart, I. T.: Changes in snowpack and snowmelt runoff for key mountain regions, Hydrol. Process., 23, 78-94, 2009.

Sugawara, M.: Tank model, Computer models of watershed hydrology, in: Water Resources Publications, edited by: Singh, V. J., Highlands Ranch, CO, USA, 1995.

Tockner, K., Ward, J. V., Arscott, D. B., Edwards, P. J., Kollmann, J., Gurnell, A. M., Petts, G. E., and Maiolini, B.: The Tagliamento River: a model ecosystem of European importance, Aquat. Sci., 65, 239-253, 2003.

Tureyen, O. I. and Akyap, E.: A generalized non-isothermal tank model for liquid dominated geothermal reservoirs, Geothermics, 40, 50-57, 2011.

USEPA: DFLOW: a tool for low flow analysis in water quality models and tools. United States Environmental Protection Agency, Washington, DC, available at: http://epa.gov/ waterscience/models/dflow/flow101.cfm (last access: 5 November 2010), 2009.

Yokoo, Y., Kazama, S., Sawamoto, M., and Nishimura, H.: Regionalization of lumped water balance model parameters based on multiple regression, J. Hydrol., 246, 209-222, 2001.

Zhang, X., Srinivasan, R., Debele, B., and Hao, F.: Runoff simulation of the headwaters of the Yellow River using the SWAT model with three snowmelt algorithms, J. Am. Water Resour. As., 44, 48-61, 2008.

Zion, M. S., Pradhanang, S. M., Pierson, D. C., Anandhi, A., Lounsbury, D. G., Matonse, A. H., and Schneiderman, E. M.: Investigation and Modeling of winter streamflow timing and magnitude under changing climate conditions for the Catskill Mountain region, New York, USA, Hydrol. Process., 25, 3289-3301, 2011. 